\title{
REDUÇÃO DE CONSUMO DE ZINCO E MELHORIA NA QUALIDADE DE ARAMES DE CAMADA PESADA*
}

Cirano Gewehr Campanher ${ }^{1}$ João Vinícius de Souza Vares ${ }^{2}$

\section{Resumo}

O presente trabalho apresenta um projeto de melhoria em processo de galvanização implantado na Gerdau Riograndense, para o controle de camada de zinco em arames de camada pesada. O trabalho realizado envolveu investimento de Engenharia para atualização tecnológica em uma linha de galvanização existente, que operava até então com controle manual de vazão de nitrogênio, gás utilizado para a conformação da camada de zinco dos arames, na saída do forno de zinco. Através da implantação do sistema automatizado foi possível aumentar a estabilidade no controle do processo, reduzindo a variabilidade na camada de galvanização dos arames, com a obtenção de arames galvanizados com qualidade superior, reduzindo também os custos de consumo de zinco.

Palavras-chave: Galvanizados; Camada pesada; Sistema de sopragem de nitrogênio.

\section{REDUCTION OF ZINC CONSUMPTION AND QUALITY IMPROVEMENT OF HEAVY COATED GALVANIZED WIRES}

\section{Abstract}

This paper presents an improvement project at galvanizing process implemented in Gerdau Riograndense, for heavy coated galvanized wires. The project involved a technological upgrade in an existing galvanizing line, which operated so far with manual control nitrogen flow, gas used for controlling the thickness of zinc coating in the wires. Through this automated system was possible to increase the stability in the process control, reducing the variability on galvanized coating, getting superior wire quality results as well as cost reduction due to less consumption of zinc.

Keywords: Galvanized wire; Heavy coating galvanized wires; Gas wiping system.

1 Engenheiro Mecânico, Assessor Técnico, Engenharia, Gerdau Aços Brasil - Gerdau Riograndense, Sapucaia do Sul, Rio Grande do Sul, Brasil.

2 Engenheiro Metalúrgico, Assistente Técnico, Tecnologia de Processos e Produtos, Gerdau Aços Brasil - Gerdau Riograndense, Sapucaia do Sul, Rio Grande do Sul, Brasil. 


\section{INTRODUÇÃO}

\subsection{Processos de galvanização a fogo}

O processo de zincagem por imersão a quente, também conhecido como processo de galvanização a fogo, está entre as técnicas mais tradicionalmente utilizadas para proteção do aço contra a corrosão, em função das propriedades conferidas ao aço, a um custo relativamente baixo. Trata-se de um processo de revestimento metálico, onde o substrato metálico (usualmente o aço) é imerso em um banho de zinco fundido, formando-se sobre o material camadas de ligas ferro-zinco e de zinco puro. Estas camadas podem ser espessas e aderentes, proporcionando ao material uma boa proteção contra a corrosão, além da melhora em seu aspecto superficial [1,2].

O processo de galvanização por imersão a quente pode ser por batelada ou contínuo.

No processo de galvanização por batelada, comumente aplicável a peças maiores e mais espessas, o material é movimentado, sendo imerso e retirado sequencialmente em tanques (banhos), onde ocorre cada etapa do processo de galvanização (limpeza, fluxagem, galvanização e passivação).

No processo contínuo de galvanização, aplicável a materiais bobinados (chapas, arames, tubos, etc.), a imersão do material nos tanques (banhos) é realizada através da tração do material por uma de suas extremidades, promovendo a sua passagem através de diversos tanques (banhos) instalados em linha [3].

\subsection{Classificação dos arames}

Os produtos galvanizados obtidos por processo contínuo são comumente classificados em dois tipos: de camada leve e de camada pesada, onde a diferença entre os dois tipos basicamente está na quantidade de zinco do revestimento, que é maior nos produtos de camada pesada, destinados a aplicações em ambientes mais corrosivos ou que requerem maior vida útil do revestimento.

Especificamente no caso de arames, emprega-se maior espessura de camadas em arames de maior diâmetro [1,2].

A massa mínima da camada de zinco em arames deve atender ao especificado em NBR 6331/2010 [4].

\subsection{Sistema de saída do banho de zinco}

No processo contínuo de galvanização, após a passagem dos arames pelo banho de zinco fundido, ocorre a etapa de conformação da camada galvanizada. O objetivo dessa etapa é remover o excesso de zinco sobre o arame, permitindo alcançar a espessura e o aspecto superficial do revestimento conforme as especificações desejadas. A referida conformação é feita, usualmente, através de um sistema de raspagem com nitrogênio, onde cada arame possui um bico de sopragem individual, por onde é soprado nitrogênio, perpendicularmente ao eixo do fio. A pressão e a vazão são pré-ajustadas conforme o diâmetro do fio, a velocidade da linha e a camada de zinco desejada [5,2].

O sistema com nitrogênio não requer intervenções constantes, e em caso de quebras na linha, a passagem do arame pode ser feita sem parada dos demais fios, uma vez que o bico se abre em duas partes, conforme ilustrado na Figura 1. 

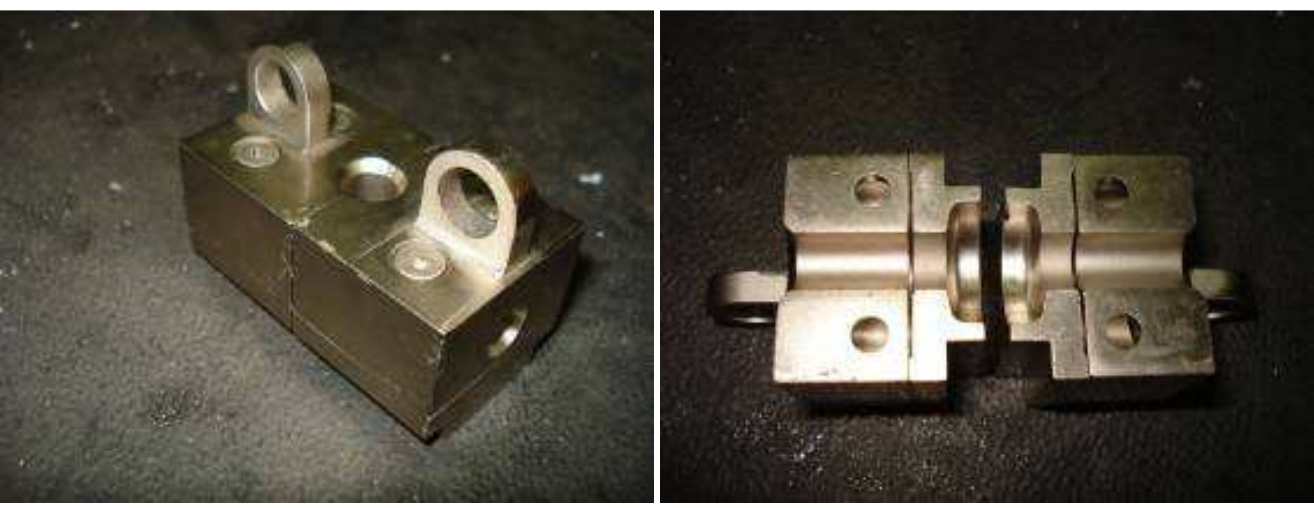

Figura 1. Bico soprador de nitrogênio.

A quantidade de zinco depositada sobre o arame depende de diversas variáveis do processo de galvanização, tais como: diâmetro dos bicos sopradores de nitrogênio, velocidade do arame, tempo de imersão no banho de zinco, pressão e vazão do nitrogênio, temperatura, condições do banho de zinco e características do arame a galvanizar.

$\mathrm{Na}$ Figura 2, pode-se observar o sistema de saída com sopro de nitrogênio e a instrumentação utilizada para seu ajuste.

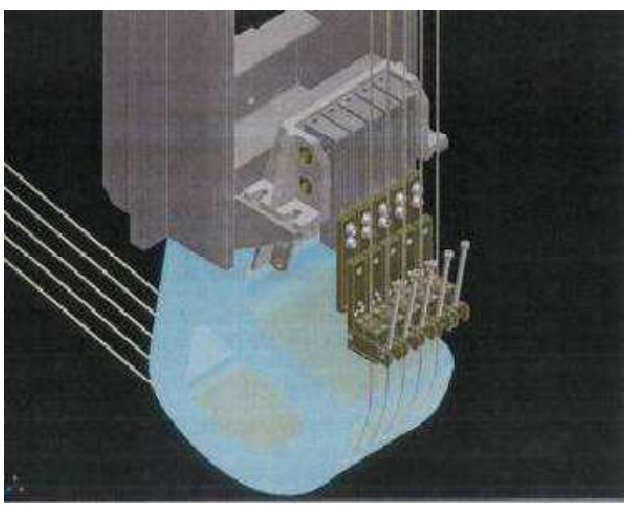

(a)

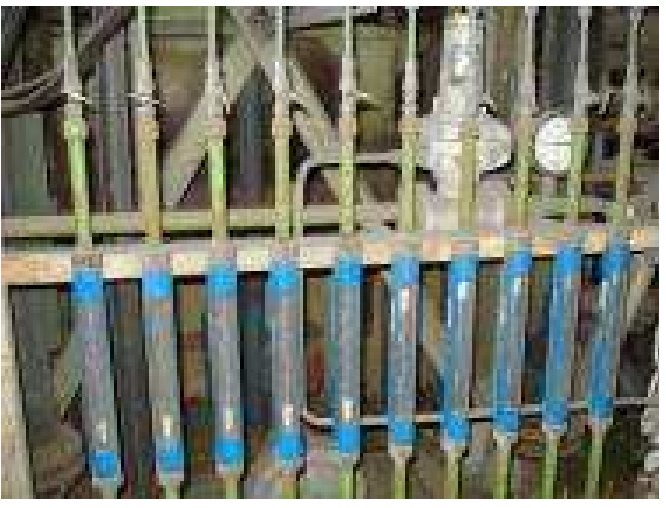

(b)

Figura 2. (a) Saída vertical dos arames e sistema de sopragem de $\mathrm{N}_{2 ;}$ (b) Ajuste manual de vazão de $\mathrm{N}_{2}$ (válvulas e rotâmetros).

Quanto maior a vazão de sopragem de nitrogênio, menor é a camada final de zinco sobre o arame. A regulagem desta vazão, em sistema manuais, normalmente, é fixada pelo operador para cada arame, mediante escolha do bico de nitrogênio mais apropriado ao diâmetro do arame e ajuste de válvulas manuais de nitrogênio, com indicação de vazão em rotâmetros.

\section{MATERIAIS E MÉTODOS}

Com vistas à otimização do processo de galvanização, na Gerdau Riograndense, foi instalado um sistema automático de controle de vazão de nitrogênio para os fios de camada pesada.

A seguir é descrito esse sistema que substituiu o sistema manual de controle de sopragem do nitrogênio existente. 


\subsection{Sistema automático de controle de camada de zinco}

O referido sistema é composto por sensores de detecção da camada de zinco, interligados a um CLP (controlador lógico programável), interface homem-máquina (IHM) e válvulas moduladoras de vazão de nitrogênio. Mediante a modulação da vazão de nitrogênio, o sistema compensa as variações do processo, assegurando uma camada de zinco mais uniforme, com a gramatura necessária, que é parametrizável pela IHM. As Figuras 3 e 4 ilustram a malha de controle:

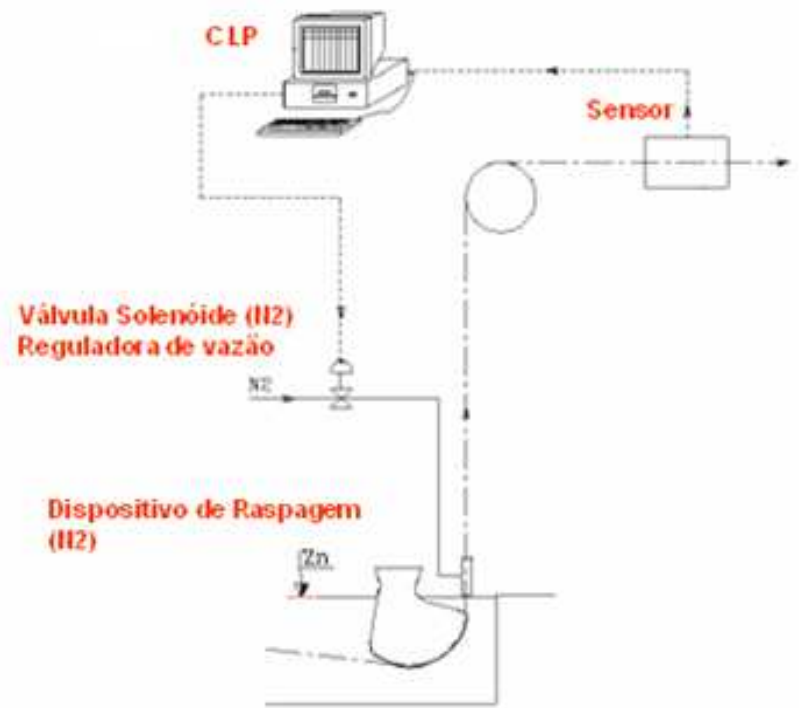

Figura 3. Visão geral do sistema automático de controle de camada galvanizada Fonte: Linha de Galvanização 2 - Gerdau Riograndense

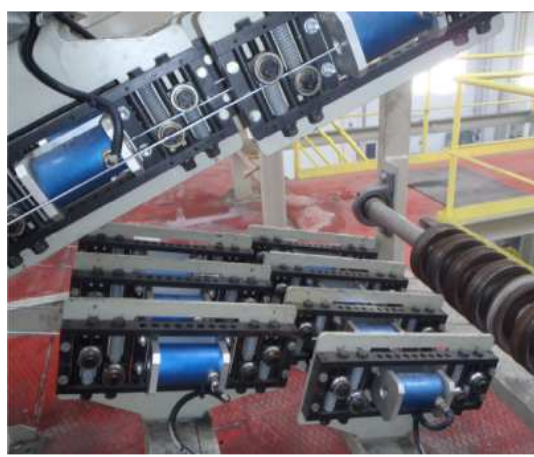

(a)

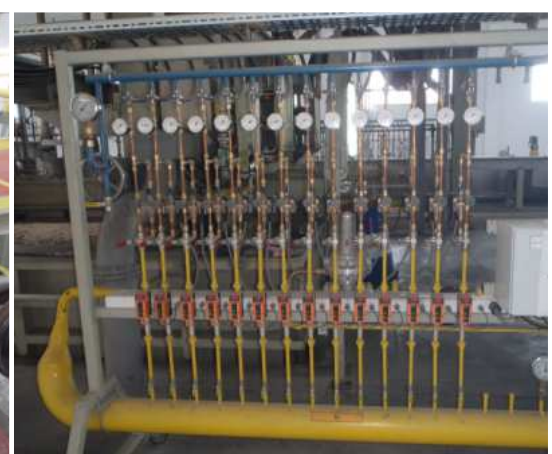

(b)

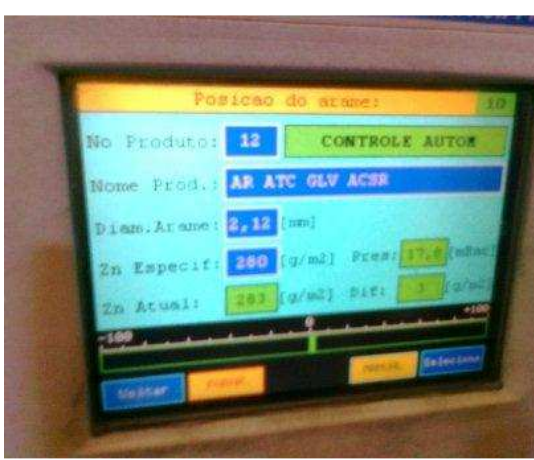

(c)

Figura 4. (a) Sensores nos fios galvanizados; (b) Válvulas moduladoras de $\mathrm{N}_{2}$; (c) $\mathrm{IHM}$ - interface homem-máquina, que permite o controle do sistema.

Com a implantação do sistema automático de controle de camada galvanizada projetou-se reduzir o desvio-padrão dos resultados de gramatura de zinco em 33\%.

\subsection{Métodos estatísticos utilizados}

Para o processamento dos dados e análises estatísticas dos resultados de camada de zinco para os arames de camada pesada que são apresentados nesse trabalho, foi utilizado o recurso computacional Minitab® Statistical Software. 


\section{RESULTADOS E DISCUSSÃO}

\subsection{Sistema de controle manual}

Em um sistema manual de controle da vazão de nitrogênio, ocorrem variações na gramatura da camada de zinco, pois as condições operacionais da linha de galvanização variam, enquanto a vazão de nitrogênio é mantida fixa. Assim, para atender com margem de segurança, à camada mínima de zinco estabelecida por norma [5], a vazão de nitrogênio é ajustada próxima ao limite mínimo. Essa prática garante uma sobrecamada de zinco que cubra todas as possíveis variações do processo. Entretanto, isso traz como resultado arames com excesso de zinco, na maior parte do volume produzido na linha.

$\mathrm{Na}$ Figura 5 pode ser visto o resultado prático da produção de um arame com excesso de zinco, que ocasiona problemas na aderência da camada galvanizada, problemas de escamação/fissuras, entre outros que afetam a qualidade superficial do arame galvanizado $[6,2]$.

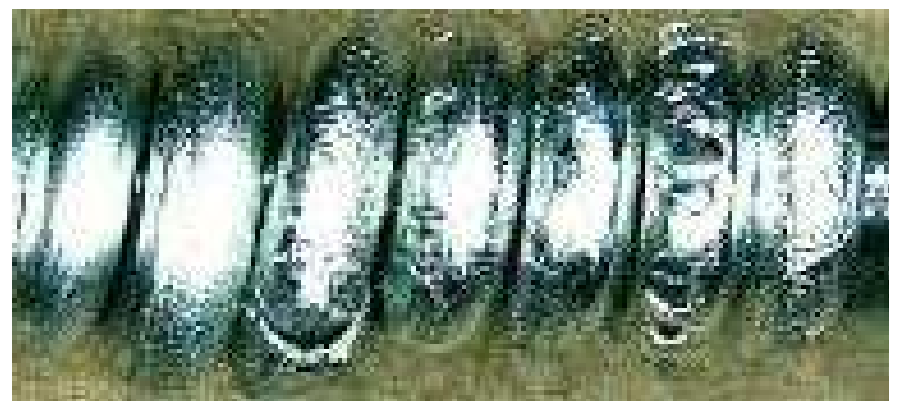

Figura 5. Problema de aderência da camada de zinco.

Fonte: amostra de arame camada pesada - Gerdau Riograndense

Nas Figuras 6, 7 e 8 podem ser verificadas as distribuições dos resultados de camada de zinco, para três diferentes arames de camada pesada, produzidos com sistema manual e sobrecamada projetada para atendimento à especificação mínima.

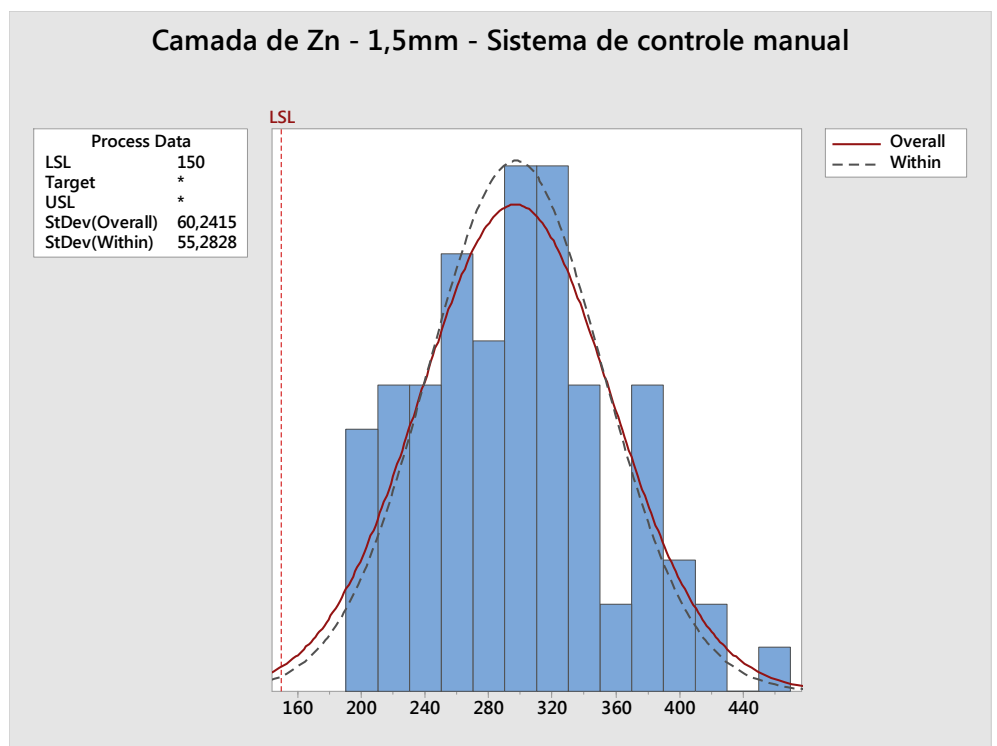

Figura 6. Distribuição dos resultados de camada de zinco para um arame com diâmetro de $1,5 \mathrm{~mm}$. 
Analisando a distribuição dos resultados de camada de zinco para um arame com diâmetro de 1,5mm, conforme Figura 6, pode-se verificar um desvio-padrão de 65,4 $\mathrm{g} / \mathrm{m}^{2}$.

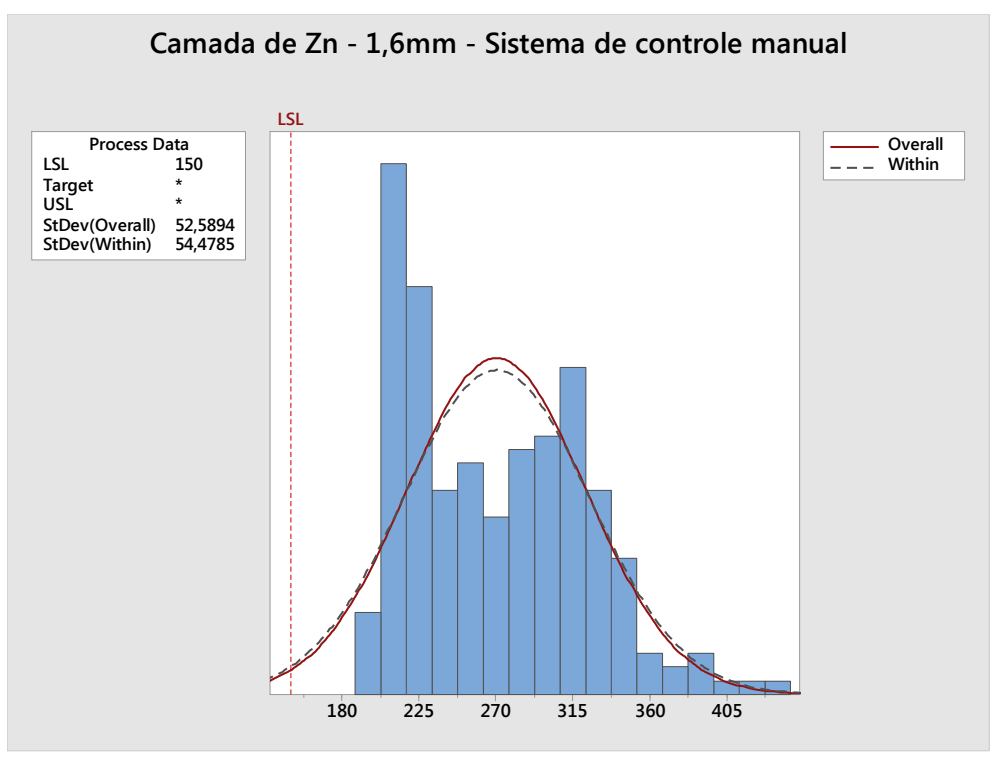

Figura 7. Distribuição dos resultados de camada de zinco para um arame com diâmetro de $1,6 \mathrm{~mm}$.

Analisando a distribuição dos resultados de camada de zinco para um arame com diâmetro de 1,6mm, conforme Figura 7, pode-se verificar um desvio-padrão de 52,9 $\mathrm{g} / \mathrm{m}^{2}$.

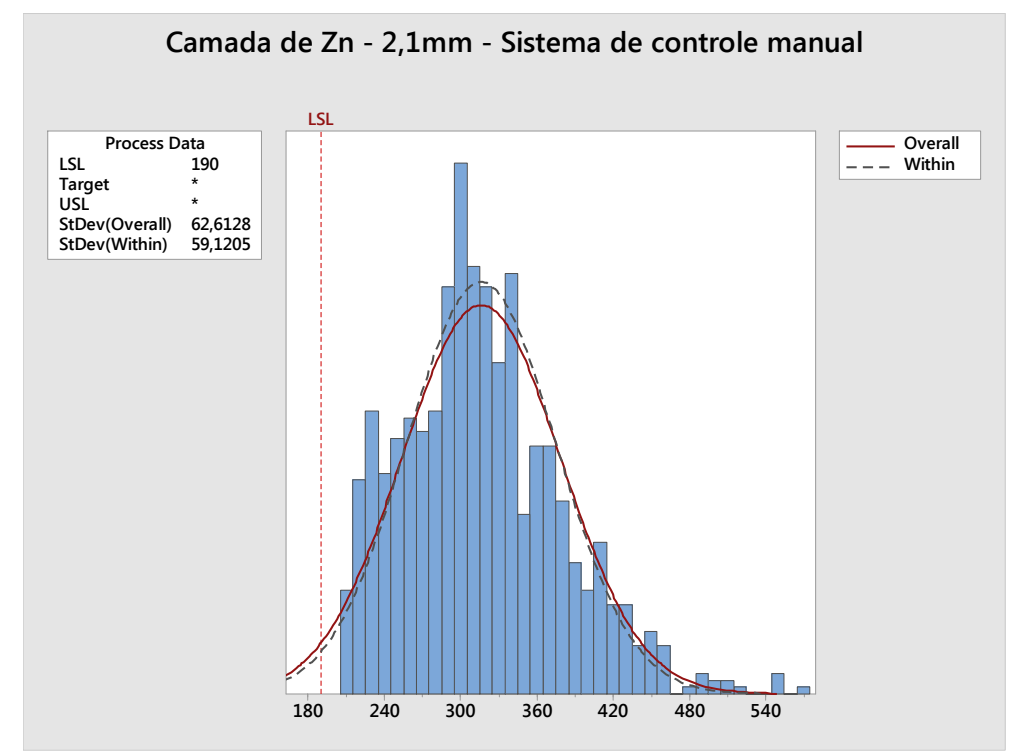

Figura 8. Distribuição dos resultados de camada de zinco para um arame com diâmetro de $2,1 \mathrm{~mm}$.

Analisando a distribuição dos resultados de camada de zinco para um arame com diâmetro de 2,1mm, conforme Figura 8, pode-se verificar um desvio-padrão de 64,5 $\mathrm{g} / \mathrm{m}^{2}$.

Com a análise das distribuições dos resultados de camada, verifica-se a elevada dispersão dos valores obtidos com o sistema de controle manual de vazão de nitrogênio. Essa condição de processo é evidenciada pelos altos valores de desviopadrão encontrados para os três diferentes arames estudados. 


\subsection{Sistema de controle automático}

A seguir são expostos os resultados de distribuição dos valores de camada de zinco, para os mesmos arames, após a implantação do sistema de controle automático da camada de zinco.

Nas Figuras 9, 10 e 11 podem ser vistas as distribuições para os arames de diâmetros $1,5 \mathrm{~mm}, 1,6 \mathrm{~mm}$ e $2,10 \mathrm{~mm}$, respectivamente.

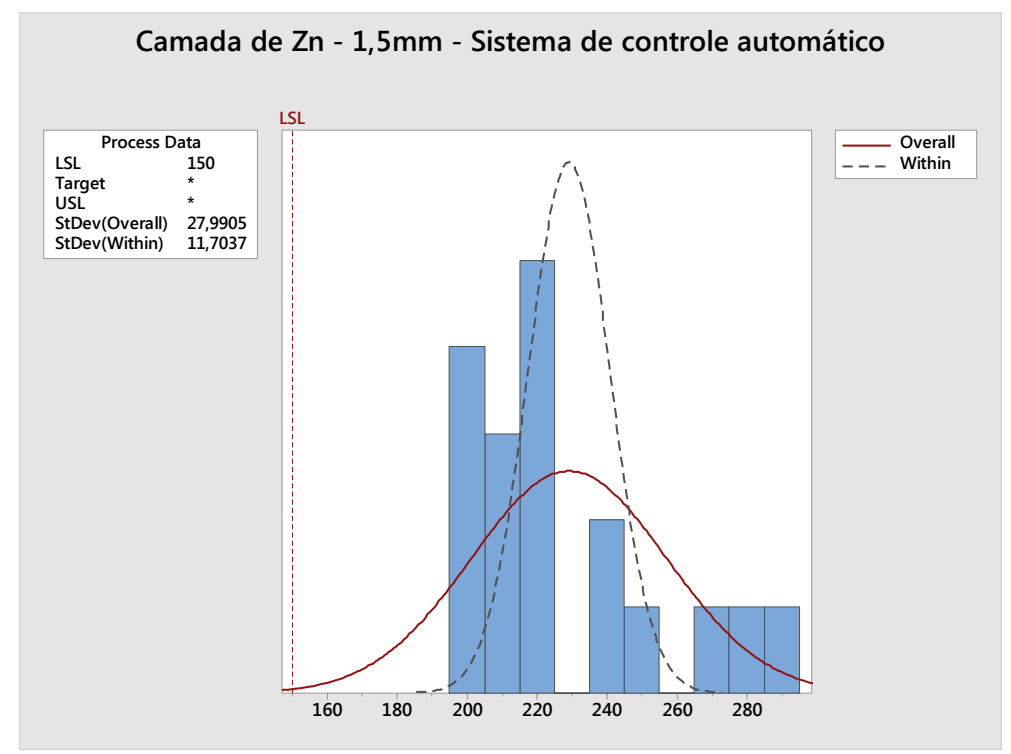

Figura 9. Distribuição dos resultados de camada de zinco para um arame com diâmetro de 1,5mm.

A partir da distribuição dos resultados de camada de zinco para um arame com diâmetro de 1,5mm, conforme Figura 9, pode-se verificar um desvio-padrão de 28,0 $\mathrm{g} / \mathrm{m}^{2}$.

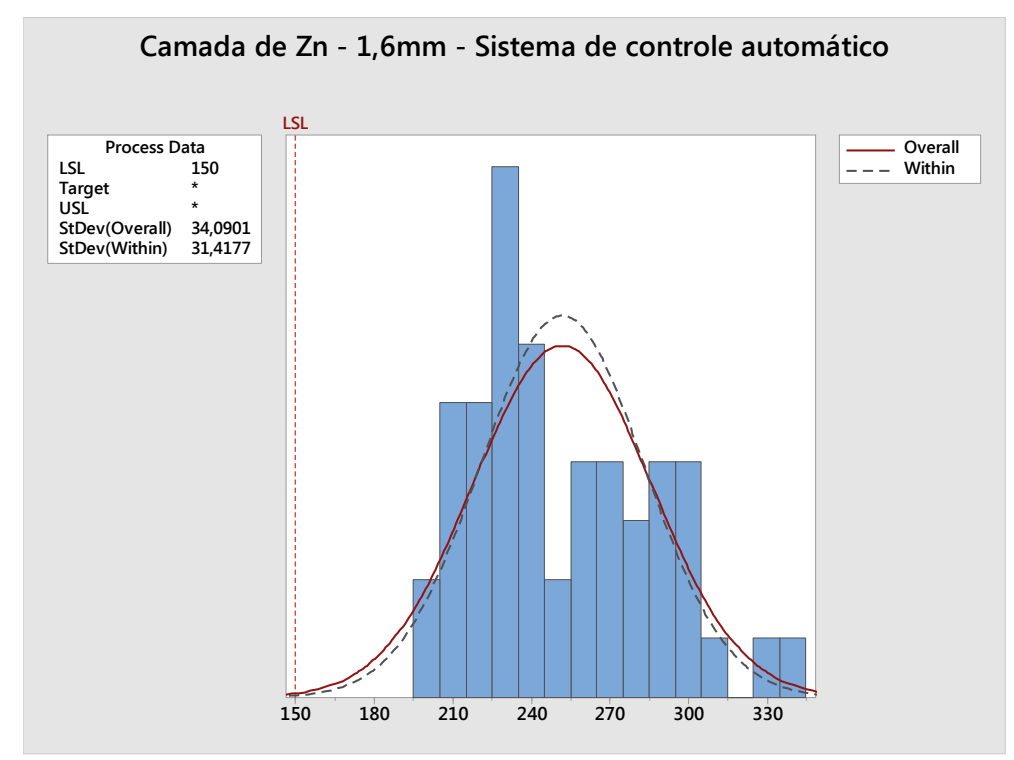

Figura 10. Distribuição dos resultados de camada de zinco para um arame com diâmetro de 1,6mm. 
A partir da distribuição dos resultados de camada de zinco para um arame com diâmetro de 1,6mm, conforme Figura 10, pode-se verificar um desvio-padrão de 34,1 $\mathrm{g} / \mathrm{m}^{2}$.

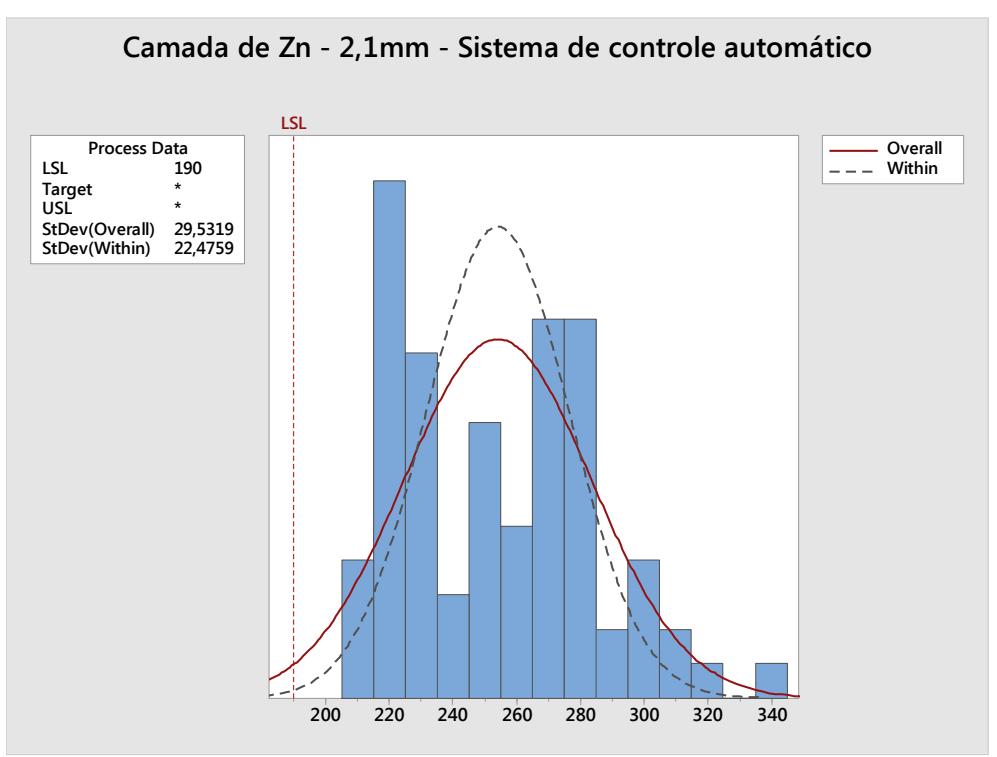

Figura 11. Distribuição dos resultados de camada de zinco para um arame com diâmetro de 2,1mm.

A partir da distribuição dos resultados de camada de zinco para um arame com diâmetro de 2,1 mm, conforme Figura 11, pode-se verificar um desvio-padrão de 29,5 $\mathrm{g} / \mathrm{m}^{2}$.

$\mathrm{Na}$ Tabela 1 consta o resumo comparativo dos resultados com o sistema manual e o sistema automático de controle de camada de zinco, obtidos a partir dos testes realizados na Galvanização da Gerdau Riograndense.

Tabela 1. Resumo comparativo dos resultados com o uso do sistema manual e automático de controle de camada de zinco

\begin{tabular}{|c|c|c|c|c|c|}
\hline \multirow{2}{*}{ Arame } & \multirow{2}{*}{$\begin{array}{c}\text { Especificação } \\
\text { mínima }\left(\mathbf{g} / \mathbf{m}^{2}\right)\end{array}$} & $\begin{array}{l}\text { Sistema } \\
\text { manual }\end{array}$ & $\begin{array}{c}\text { Sistema } \\
\text { automático }\end{array}$ & \multirow{2}{*}{$\begin{array}{l}\text { Redução do } \\
\text { desvio- } \\
\text { padrão (\%) }\end{array}$} & \multirow{2}{*}{$\begin{array}{c}\text { Redução da } \\
\text { média (\%) }\end{array}$} \\
\hline & & $\begin{array}{l}\text { Desvio- } \\
\text { padrão } \\
\left(\mathrm{g} / \mathrm{m}^{2}\right)\end{array}$ & $\begin{array}{l}\text { Desvio- } \\
\text { padrão } \\
\left(\mathbf{g} / \mathbf{m}^{2}\right)\end{array}$ & & \\
\hline $1,5 \mathrm{~mm}$ & 150 & 60,2 & 28,0 & $-54 \%$ & $-22 \%$ \\
\hline $1,6 \mathrm{~mm}$ & 150 & 52,6 & 34,1 & $-35 \%$ & $-6 \%$ \\
\hline $2,1 \mathrm{~mm}$ & 190 & 62,6 & 29,5 & $-53 \%$ & $-19 \%$ \\
\hline
\end{tabular}

Com o emprego do sistema automático de controle obteve-se uma redução média de $47 \%$ na dispersão dos resultados, representada pela diminuição do desviopadrão das distribuições dos valores de camada de zinco para os três diferentes arames estudados. Também foi possível perceber uma redução de $16 \%$ nos valores médios de camada de zinco. 


\section{CONCLUSÃO}

Analisando os resultados de camada de zinco em arames de camada pesada obtidos com o sistema automático de controle frente ao sistema manual, pode-se evidenciar claramente a diminuição da dispersão dos valores medidos nos arames galvanizados - redução média de $47 \%$.

Com a redução da dispersão e da produção com sobrecamada, houve redução no consumo de zinco em 19\% e também melhora no aspecto superficial dos arames.

Outro importante ganho foi a redução da influência do fator humano no controle da camada de zinco, pois o sistema automático faz a modulação da vazão e o controle da camada conforme os parâmetros medidos pelo próprio sistema, minimizando, assim, a necessidade de intervenções operacionais.

\section{Agradecimentos}

Agradecemos aos colegas Marcos Augusto Zilles Mattiello e Luciana de Carvalho Affonso por possibilitarem a realização desse trabalho. Aos colegas Elidiane de Souza Jaques e João Vitor Mokan pelas contribuições na revisão desse trabalho. Agradecemos também ao consultor técnico Marcos Alberto Moschen Pinto pelas contribuições e pelo incentivo.

\section{REFERÊNCIAS}

1 GRACIA Jr., LORENO e MALLET, Ana. Curso de Galvanização do Grupo Gerdau. 1985, 1989, 1993.

2 CAMPANHER, C.G. Otimização experimental em processo de galvanização de arames de camada pesada. UFRGS. Porto Alegre, RS (2009) p.1 - 97.

3 PANNONI, Fabio Domingos. Princípios da galvanização a fogo. Disponível em: < www.ztec.ind.br/pdf/principios/principios.pdf >. Acesso em 06 mar 2015.

$4 \quad$ NBR 6331. Arame de aço de baixo teor de carbono, zincado, para uso geral. Out 2010.

5 FIB LE FOUR INDUSTRIEL BELGE sa-nv, The Dynamic wiping: A solution to the rationalization of Zinc consumption in vertical galvanizing. FIB NEWS №7, 2003.

6 MARDER, A.R. The metallurgy of zinc-coated steel. Progress in Materials Science, Volume 45 (2000) p. $191-271$. 